\title{
Dementia: Risk Factors and Updated Review
}

\author{
Nepal H ${ }^{1}$, Jeffrey $B^{2}$, Bhattarai $\mathbf{M}^{3}$
}

1. PGY-5, Department Of Psychiatry, Southern Illinois University School of Medicine, Springfield, USA 2.Assistant Professor, Department Of Psychiatry, Southern Illinois University School of Medicine, Springfield, USA 3. Assistant Professor, Department of Internal Medicine Southern Illinois University School of Medicine, Springfield, USA

E-mail *Corresponding author : hitekshya@gmail.com

\begin{abstract}
With the tremendous rise in the aging population around the world, the prevalence of Maior Neurocognitive Disorders is skyrocketing. In the same manner, the burden of the morbidity and mortality associated with the such disorders has been a global health problem. Most of the time, the cause of Major Neurocognitive Disorder is unknown. Our review article is an attempt to summarize the likely modifiable risk factors associated with the disorder. In this manner there could be insight into further confirmatory and exploratory evidence based studies of these factors for early intervention to prevent and delay the progression of full blown disease. Among the modifiable risk factors, the ones that have been discussed here are smoking, activity both physical and cognitive, cardiovascular risk factors, depression, traumatic brain injury and sleep.
\end{abstract}

\section{Keywords: Major Neurocognitive Disorder, Modifiable Risk Factors}

\section{INTRODUCTION}

While there are many causes of Major Neurocognitive Disorder including sudden, monophasic brain injury ("static encephalopathies"), this article deals with those disorders in which there is a progressive neurocognitive course caused by a combination of genetic and environmental risk factors leading to insidious and functional decline until death (1). Many risk factors for the occurrence and progression of dementia have been identified; early intervention may prevent and delay the progression of full blown dementia.

\section{PREVALENCE}

There has been a demographic shift in the trajectory of human aging, mainly due to people living longer and the aging of the "baby boomer" generation with relatively fewer newborns (2). A Delphi consensus study revealed that the prevalence of dementia rapidly increases from approximately $2-3 \%$ among those aged $70-75$ years to $20-25 \%$ among those aged 85 years or more (3). At present the global prevalence of dementia is estimated at $5-7 \%$ of the population aged above 60 years (4). There is variation in the prevalence and distribution of dementia around world probably due to cultural and socioeconomic differences among nations (5). Dementia was considered a less significant problem in the past. But today, with an aging populace, dementia represents a significantly greater societal and economic burden (6). In particular, it is a more widely recognized problem in low- and middle- income countries as this is the first time that their population is achieving a longer life expectancy (7). In many of these countries the incidence of dementia is expected to drupelet by 2050 (5).

\section{MODIFIABLE RISK FACTORS}

The presence of modifiable risk factors helps to understand the mechanisms of mild cognitive decline and dementia (8). It also helps to identify 
those individuals who are at greatest risk for developing the dementia. Thus, early intervention could be provided for initiating treatment and prevention for those high risk groups. Different studies reveal similar modifiable risk factors which include diabetes, mid-life obesity, mid-life hypertension, smoking, history of depression, sleep disturbance, hyperlipidemia, and traumatic brain injury (8-11).

\section{SMOKING AND DEMENTIA}

Smoking is a modifiable risk factor for several chronic illnesses; however, its long-term relationship with dementia is still controversial (12). Numerous past studies exploring the effect of smoking on cognitive outcomes were inconclusive as the majority of them showed weak or null associations (13-17). However, a number of other cohort studies revealed positive association between smoking and risk of developing dementia (18-21).

\section{CARDIOVASCULAR RISK FACTORS}

Several lines of evidence suggests strong correlation at mid-life of cardiovascular disease with dementia $(9,22,23)$. Cardiovascular risk must be elevated over an extended time to impact the risk of dementia (23). The factors associated with increased cardiovascular risk during mid-life include obesity, diabetes, hypertension, dyslipidemia (24). While it was thought at one time that such factors raised only the risk of vascular dementias, it is now established that these same factors mitigate toward developing Alzheimer type dementia through enhanced accumulation of associated toxic proteins through cardiovascular risk factors at the microvascular level (8). A recent clinical study revealed that dementia is closely associated with cardiovascular disease, especially hypertension and atrial fibrillation (25). Hyperinsulinemia and elevated systolic blood pressure independently predicted white matter hyperintensities with associated cognitive decline in the middle-aged offspring of the patients with dementia (24).The additive effects of all the components of the metabolic syndrome is found higher than the individual component for the development of dementia in late life. Having more criteria for the metabolic syndrome raises dementia risk greater than having fewer criteria.

Vlad and co-workers found a positive correlation between long-term nonsteroidal antiinflammatory (NSAID) use and a lower incidence of Alzheimer's type dementia in a study of 50,000 veterans (26).

\section{PHYSICAL AND MENTAL ACTIVITY AS PREVENTIVE FACTORS}

The evidence linking physical inactivity with dementia risk has been largely based on educated assumptions. The common saying, "use it or lose it" makes common sense to many, but what established evidence exists for recommending physical activity as a protective factor. There are different mechanisms of protective effect of physical activity on cognition which include proper cerebral blood flow (27), elevation of aerobic capacity, adequate cerebral nutrient supply and brain-derived neurotropic factor that increases neuronal survival, enhances learning, and is a protective factor for cognitive decline $(28,29)$.

Animal models of neuropsychiatric disorders have lended some objective support to the value of physical activity on prevention (30). For example, a murine model of hippocampal found increased cell numbers in animals which exercised (running paradigm) than controls (31). In an associated human study, number of footsteps was positively correlated with less decline on the Mini-Mental State Exam (32). Other studies have suggested that exercise be recommended not only as primary prevention but also as secondary prevention due to already demonstrated benefits on cardiovascular risk factors (33).

There is much interest in the potential value of cognitive stimulation strategies as a protective factor in dementia (34). Cognitive reserve appears to have a protective effect as demonstrated in Snowden's famous Nun Study (48). Cognitive reserve could act as a buffer to prevent destruction by amyloid, tau, and other toxic proteins (35). An important question, however, is can cognitive reserve be successfully enhanced by various mental activities (e.g., videogaming) to the point that it has demonstrable preventative effects on dementia 
risk (36)? Recent meta-analyses indicate that computerized cognitive training is efficacious in global cognition, in select cognitive domains, and in psychosocial functioning in mild cognitive disorder (37), however evidence for a protective role in dementia remains limited.

\section{SLEEP AND COGNITIVE FUNCTION}

Hallmark symptoms of Alzheimer's include impaired hippocampus-dependent episodic memory, disrupted sleep, and altered circadian rhythms. Sleep and circadian disruption can impair hippocampus-dependent learning and memory (38). Brain interstitial fluid A-beta amyloid (the toxic form of amyloid associated with Alzheimer's type dementia) has been found to correlate with the degree of wakefulness in a murine model of sleep effects (39). Interstitial fluid A-beta levels are higher in acute sleep deprivation. Other studies indicated women in the lowest quartile of average sleep efficiency $(<74 \%)$ had a 1.5 -fold higher odds of developing cognitive decline (41). Longer average sleep latency and greater variability in both sleep efficiency and total sleep time were also associated with greater marked cognitive decline (40). Past studies have demonstrated that sleep disordered breathing is associated with increased risk of cognitive decline (41).

\section{DEPRESSION AND COGNITION}

Depression is the most common reason to seek psychiatric attention in elderly. Depression has been directly linked to decreased cognition. Dinez and co-workers studied late-life depression and risk of vascular dementia and Alzheimer's disease. In the 23 cohort studies included, their systematic review and metaanalysis of community-based cohort studies demonstrated that late-life depression was associated with a significant risk of all-cause dementia (42). This raises the question of whether depression treatment or prevention can reduce dementia risk. In a retrospective study using a mouse model, administration of a selective serotonin reuptake inhibitor led to reduction of interstitial fluid A-beta levels (43). This avenue of dementia prevention is ripe for further study.

\section{TRAUMATIC BRAIN INJURY AND DEMENTIA}

Age at injury is associated with the long-term cognitive outcome of traumatic brain injuries (44). Traumatic brain injury commonly results in diffuse axonal injury, accumulation of Amyloid and Tau, reduction in synaptic efficacy, breakdown of the blood brain barrier, inflammatory microglial activation, and cell death as well. Moderate to severe brain injury, including repetitive concussive injuries has been demonstrably associated with early cognitive decline (45). This study finding was implied in a 9 year Veteran study in which greater risk of cognitive degeneration is associated with a comorbid neuropsychiatric conditions including depression, post-traumatic stress disorder, and cerebrovascular disease (46).

\section{FUTURE DIRECTION}

There are numerous risk factors for dementia; however, the potentially important modifiable risk factors having consistent evidence of an association with dementia are diabetes, midlife hypertension, midlife obesity, physical inactivity, depression, smoking, and low educational attainment. If prevalence of the risk factors were reduced by $10 \%$ or $20 \%$ per decade over these 40 years, a substantial proportion of Alzheimer's disease cases could, theoretically be prevented (44). Thus by 2050, it has been estimated that a $10 \%$ reduction in these risk factors would decrease the incidence of Alzheimer's cases in the United States 8.7\%, and globally by $8.3 \%$ (8.8 million) (44).

\section{CONCLUSION}

There is a high potential impact for implementing strategies focused on the modifiable risk factors for cognitive decline leading to mild cognitive impairment and dementia. Thus, addressing these risk factors at an appropriate time is highly recommended. Further confirmatory and exploratory evidence based studies are needed given the massive burden facing the global health burden.

\section{CONFLICT OF INTEREST}

The author reports no conflicts of interest in this work, and is solely responsible for the content 
and writing of this paper. No funding has been received for this work.

\section{REFERENCES:}

1. Tang EY, Harrison SL, Errington L, et al. Current developments in dementia risk prediction modelling: An updated systematic review. PLoS One. 2015;10: e0136181.

2. Sperling RA, Aisen PS, Beckett LA, et al. Toward defining the preclinical stages of Alzheimer's disease: Recommendations from the National Institute on Aging-Alzheimer's Association workgroups on diagnostic guidelines for Alzheimer's disease. Alzheimers Dement. 2011;7(3): 280-292.

3. Ferri $C P$, Prince $M$, Brayne $C$, et al. Global prevalence of dementia: a Delphi consensus study. The Lancet. 2005;366( 9503):2112-2117.

4. World Alzheimer Report. Viewed April 2, 2017 $<\underline{\text { http://www.worldalzreport2015.org/> }}$

5. Rizzi L, Rosset I, Roriz-Cruz M. Global Epidemiology of Dementia: Alzheimer's and Vascular Types. BioMed Research International. 2014;1:1-8.

6. Rockwood K. Chronic Medical Disease \& Cognitive Aging: Toward a Healthy Body and Brain. Can Geriatr J. 2013;16(3):143-144.

7. Wu YT, Brayne C, Matthews FE. Prevalence of dementia in East Asia: a synthetic review of time trends. Int J Geriatr Psychiatry. 2015;30:793-801.

8. Barnes DE, Yaffe K. The projected effect of risk factor reduction on Alzheimer's disease prevalence. Lancet Neurol. 2011;10(9):819-828.

9. Baumgart $M$, Snyder, HM, Carrillo MC, et al. Summary of the evidence on modifiable risk factors for cognitive decline and dementia: A populationbased perspective. Alzheimer's \& Dementia. 2015;11(6):18-726.

10. Cooper C, Sommerlad A, Lyketsos CG, Livingston G. Modifiable predictors of dementia in mild cognitive impairment: a systematic review and meta-analysis. Am I Psychiatry. 2015;172(4):323-34.

11. Xu W, Tan L, Wang HF, Iiang $T$, Tan MS, Tan L, Zhao QF, Li IQ, Wang I, Yu JT. Meta-analysis of modifiable risk factors for Alzheimer's disease. I Neurol Neurosurg Psychiatry. 2015;86(12):12991306.

12. Beydoun MA, Beydoun HA, Gamaldo AA, et al. Epidemiologic studies of modifiable factors associated with cognition and dementia: systematic review and meta-analysis. BMC Public Health. 2014;24(14):643.

13. 13.Peters $R$, Beckett $N$, Geneva $M$, Tzekova $M$, Lu FH, Poulter R, Gainsborough N, Williams B, de Vernejoul MC, Fletcher A, Bulpitt C. Sociodemographic and lifestyle risk factors for incident dementia and cognitive decline in the HYVET. Age Ageing. 2009;38:521-527.

14. Solfrizzi V, Panza F, Colacicco AM, et al. Italian Longitudinal Study on Aging Working Group. Vascular risk factors, incidence of $\mathrm{MCI}$, and rates of progression to dementia. Neurology. 2004;63:18821891.

15. Edelstein SL, Kritz-Silverstein D, Barrett-Connor E. Prospective association of smoking and alcohol use with cognitive function in an elderly cohort. I Womens Health. 1998;7:1271-1281.

16. Doll R, Peto R, Boreham J, et al. Smoking and dementia in male British doctors: prospective study. BMJ. 2000;320:1097-1102.

17. Chen WT, Wang PN, Wang SJ, et al. Smoking and cognitive performance in the community elderly: a longitudinal study. J Geriatr Psychiatry Neurol. 2003;16:18-22.

18. Rusanen $M$, Kivipelto $M$, Quesenberry $C P J r$, et al. Heavy smoking in midlife and long-term risk of Alzheimer disease and vascular dementia. Arch Intern Med. 2011;171:333-339.

19. Ronnemaa E, Zethelius B, Lannfelt L, et al. Vascular risk factors and dementia: 40-year follow-up of a population-based cohort. Dement Geriatr Cogn Disord. 2011;31:460-466.

20. Alonso A, Mosley TH Jr, Gottesman RF, et al. Risk of dementia hospitalisation associated with cardiovascular risk factors in midlife and older age: the Atherosclerosis risk in communities (ARIC) study. J Neurol Neurosurg Psychiatry. 2009;80:1194-1201.

21. Rusanen M, Rovio S, Ngandu T, et al. Midlife smoking, apolipoprotein $E$ and risk of dementia and Alzheimer's disease: a population-based cardiovascular risk factors, aging and dementia study. Dement Geriatr Cogn Disord. 2010;30:277284.

22. Yaffe K, Vittinghoff E, Pletcher MJ, et al. Early adult to midlife cardiovascular risk factors and cognitive function. Circulation. 2014;129(15):1560-1567.

23. Reis JP, Loria CM, Launer LJ, et al. Cardiovascular health through young adulthood and cognitive functioning in midlife., Ann Neurol. 2013;73(2):170179.

24. Hawkins KA et al. Hyperinsulinemia and elevated systolic blood pressure independently predict white matter hyperintensities with associated cognitive decrement in the middle-aged offspring of dementia patients, Metab Brain Dis. 2017

25. Sasaki Y, Ikeda Y, Ohishi M. Cardiovascular Disease, as a Risk Factor for Dementia. Brain Nerve. 2016;68(7):729-736.

26. Vlad SC, Miller DR, Kowall NW, et al. Protective effects of NSAIDs on the development of Alzheimer disease. Neurology. 2008;70(19):1672-1677.

27. Rogers RL, Meyer JS, Mortel KF. After reaching retirement age physical activity sustains cerebral perfusion and cognition. I Am Geriatr Soc. 1990;38:123-128.

28. Spirduso WW. Physical fitness, aging, and psychomotor speed: a review. I Gerontol. 1980;35:850-865. 
29. Cotman CW, Engesser-Cesar C. Exercise enhances and protects brain function. Exerc Sport Sci Rev. 2002;30:75-79.

30. Nestler EJ, Hyman SE. Animal Models of Neuropsychiatric Disorders. Nature neuroscience. 2010;13(10):1161-1169.

31. van Praag $H$, Kempermann G, Gage FH. Running increases cell proliferation and neurogenesis in the adult mouse dentate gyrus. Nature Neuroscience. 1999;2:266-270.

32. Yaffe K, Barnes D, Nevitt $M$, et al. A Prospective Study of Physical Activity and Cognitive Decline in Elderly Women Who Walk. Arch Intern Med. 2001;161(14):1703-1708.

33. Lautenschlager NT, Cox KL, Flicker L, et al. Effect of physical activity on cognitive function in older adults at risk for Alzheimer disease: a randomized trial. JAMA. 2008;300(9):1027-1037.

34. Stern Y. Cognitive Reserve and Alzheimer Disease. Alzheimer Dis Assoc Disord . 2006;20:112-117.

35. Rebok GW, Ball K, Guey LT, et al. Ten-year effects of the advanced cognitive training for independent and vital elderly cognitive training trial on cognition and everyday functioning in older adults. J Am Geriatr Soc. 2014;62(1):16-24.

36. Anguera JA, Boccanfuso J, Rintoul JL, et al. Video game training enhances cognitive control in older adults. Nature. 2013;501(7465):97-101.

37. Hill NT, Mowszowski L, Naismith SL, et al. Computerized Cognitive Training in Older Adults with Mild Cognitive Impairment or Dementia: A Systematic Review and Meta-Analysis. Am J Psychiatry. 2017;174(4):329-340.

38. Kent BA, Mistlberger RE. Sleep and hippocampal neurogenesis: Implications for Alzheimer's disease. Front Neuroendocrinol. 2017;3022(17):30010-30019.

39. Kang JE, Lim MM, Bateman RJ, et al. Amyloid-beta dynamics are regulated by orexin and the sleep-wake cycle. Science. 2009;326(5955):1005-1007.

40. Diem SJ, Blackwell TL, Stone KL, et al. Measures of Sleep-Wake Patterns and Risk of Mild Cognitive Impairment or Dementia in Older Women. Am J Geriatr Psychiatry. 2016;24(3):248-258.

41. Yaffe K, Laffan AM, Harrison SL, et al. Sleepdisordered breathing, hypoxia, and risk of mild cognitive impairment and dementia in older women. JAMA. 2012;306(6):613-619.

42. Diniz BS, Butters MA, Albert SM, et al. Late-life depression and risk of vascular dementia and Alzheimer's disease: systematic review and metaanalysis of community-based cohort studies. $\mathrm{Br} \mathrm{J}$ Psychiatry. 2013;202(5):329-335.

43. Cirrito JR, DisabatoJL, Restivo DK, et al. Serotonin signaling is associated with lower amyloid- $\beta$ levels and plaques in transgenic mice and humans. Proc. Natl Acad Sci. 2011;108:14968-14973.

44. Li W, Risacher SL, McAllister TW, et al. Age at injury is associated with the long-term cognitive outcome of traumatic brain injuries. Alzheimer's $\mathcal{E}$
Dementia: Diagnosis, Assessment $\mathcal{E}$ Disease Monitoring. 2017;6:196-200.

45. Himanen $L$, Portin $R$, Isoniemi $H$, et al. Longitudinal cognitive changes in traumatic brain injury: a 30year follow-up study. Neurology. 2006;66:187-192.

46. Barnes DE, Kaup A, Kirby KA, et al. Traumatic brain injury and risk of dementia in older veterans. Neurology. 2014;83(4):312-319.

47. Norton S, Matthews FE, Barnes DE, et al. Potential for primary prevention of Alzheimer's disease: an analysis of population-based data. Lancet Neurol. 2014;13(8):788-794.

48. Snowden, D. Aging with Grace. Bantam Books, (New York, 2001). 